\title{
A QUESTÃo FRONTEIRIÇA COMO MITO FUNDADOR DO ACRE E DOS ACREANOS
}

\author{
Maria de Jesus Morais ${ }^{1}$
}

RESUMO: Com o presente artigo tem-se o objetivo de articular discussões em torno da invenção de uma certa "acreanidade" como parte do projeto de poder do grupo político que tem gerenciado a máquina pública do estado do Acre, desde o ano de 1999, em torno do autodenominado "governo da floresta". A partir das formulações de Orlandi (2006), Chauí (2007) e Albuquerque Jr. (2003), o foco da análise parte do mito fundador do "Acre" e do "acreano", a "Revolução Acreana, que articulada ao movimento autonomista que reivindicava a passagem do Acre território federal a Acre estado e pelos processos históricos de luta pela terra, protagonizadas por trabalhadores seringueiros e indígenas, constituem o pano de fundo de uma memória histórica que, amalgamada pelo discurso oficial, é utilizada para legitimar os interesses daqueles que mantêm empatia com a "história dos vencedores".

PALAVRAS-CHAVE: Acreanidade. Mito Fundador. Revolução Acreana. Governo da Floresta. Discurso.

A acreanidade, termo que define a identidade do acreano, é uma construção do grupo político "Governo da Floresta" que reinventa os eventos históricos que dão sustentação a essa construção identitária. A acreanidade possui como "mito fundador" a Revolução Acreana que funda o Acre como unidade territorial e, o acreano, o protagonista da Revolução. Isto significa dizer que a questão da incorporação do Acre ao Brasil é o evento histórico que sustenta este discurso identitário.

O discurso construtivo da acreanidade é ancorado na ocupação territorial dos altos rios da Amazônia Sul-Ocidental onde é destacado o papel que tiveram os brasileiros na bacia do Rio Acre na definição da fronteira política entre Brasil, Bolívia e Peru.

A questão fronteiriça, como ressaltado em Raffestin (1993), deve ser compreendida a partir de sua historicidade, uma vez que o sen-

${ }^{1}$ Doutora em Geografia, Professora da Universidade Federal do Acre. 
tido de fronteira muda ao longo do tempo. E essa mudança é detrimento das modificações sociopolíticas e socioeconômicas. Os limites e fronteiras refletem o poder daqueles que moldam, influenciam ou controlam atividades (SACK, 1986).

A fronteira política em tela foi definida no início do século XX, após 04 anos de conflitos e tensões entre os "brasileiros do Acre" e o governo boliviano, no contexto econômico da produção da borracha natural. Naquele momento a chegada dos nordestinos aos altos rios, que hoje formam o Acre, deslocou a fronteira política definida pelo Tratado de Ayacucho de 1867, alargando o território de soberania brasileira. Foi através da extração do látex e a conseqüente migração que levou a mudanças na fronteira política entre os três países. O Tratado de Petrópolis, de 1903, definiu a fronteira com a Bolívia e o Tratado do Rio de Janeiro, de 1909, definiu a fronteira com o Peru. Esses tratados fronteiriços tinha o sentido de definir o território de atuação dos Estadosnação. Naquele momento a Amazônia era a maior produtora de borracha natural e a área que foi incorporada ao Brasil e que hoje corresponde ao Estado do Acre estava sendo explorada por brasileiros (MORAIS, 2008).

A questão fronteiriça entre Bolívia e Brasil ou a "Guerra del Acre" é iniciada quando a demanda por borracha crescia no mercado internacional, atraindo levas de migrantes nordestinos para os seringais que passaram a ocupar, nos "territórios incontestavelmente bolivianos" pelo Tratado de Ayacucho (1867). Naquele momento o governo boliviano tenta tomar posse das terras ao sul da linha-limite Madeira-Javari, nos primeiros dias do ano de 1899 instalando um posto aduaneiro nas margens do Rio Acre em seringal de brasileiro.

A deposição do Cônsul boliviano em terras ocupadas por brasileiros do Rio Acre foi a "Primeira insurreição" dos brasileiros. No manifesto de $1^{\circ}$ de maio de 1899 , assinado por cinquenta pessoas (a maioria seringalistas) reivindicava-se a saída da representação boliviana (CARVALHO, 2002[1904]).

A "Segunda insurreição", denominada de "República de Galvez”, também ocorreu em 1899, quando o espanhol Luiz Galvez Rodrigues Arias proclama o Estado Independente do Acre. Essa insurreição foi contra o acordo EUA-Bolívia, o qual estabelecia que os EUA questionaria junto ao Brasil 
o pleno reconhecimento dos direitos da Bolívia aos territórios do Acre e Purus e, ainda, se comprometia a fornecer numerário e material bélico em caso de guerra entre os dois países. A República de Galvez fracassa dado os desentendimentos com os governadores dos Estados do Pará e Amazonas, pela falta de apoio do governo brasileiro aos "seringueiros revolucionários" e pela oposição da Bolívia. Luiz Galvez é destituído do posto e deportado pela marinha brasileira oito meses depois, e o território em questão foi restituído à Bolívia.

A "Expedição dos Poetas" foi à terceira tentativa de expulsar os bolivianos do Acre. Mas a inexperiência militar dos revoltosos e sua falta de organização, fizeram com que essa expedição fosse rapidamente derrotada pelas forças bolivianas.

A quarta insurreição, que é a fase sangrenta da Revolução Acreana, corresponde à fase da luta armada liderada por Plácido de Castro. $\mathrm{Na}$ construção do mito fundador do Acre, o termo Revolução Acreana é sempre mais enfático no que se refere à batalha comandada por Plácido de Castro, isto é, de 06 de agosto de 1902 a 24 de janeiro de 1903. Essas duas datas correspondem, respectivamente à conquista de Mariscal Sucre (hoje Xapuri) e a conquista de Puerto Alonso (hoje Porto Acre), que estavam em posse dos bolivianos. Contudo, os conflitos e tensões fronteiriços entre seringueiros (nordestinos) e bolivianos e peruanos iniciaram bem antes, em 1899, e terminara muito depois com a assinatura do Tratado do Rio de Janeiro, em 1909, com o Peru.

A Batalha comandada por Plácido de Castro inicia-se, portanto com a tomada de Marsical Xucre e termina com a tomada de Puerto Alonso. Após o primeiro combate do exército de seringueiros segue a Revolução até culminar com a batalha de janeiro de 1903.

O combate de Porto Acre ocorreu de 15 a 24 de janeiro de 1903. E é considerada a batalha mais importante da Revolução Acreana, ou seja, aquela que caracteriza a vitória territorial dos brasileiros do Acre sobre os bolivianos. Sendo sempre ressaltada a "força do exército de seringueiros comandados por Plácido de Castro e outros seringalistas", e o coroamento de

"O termo "Revolução" é uma força de expressão, que atende mais ao senso comum e à tradição local que a sua significação conceitual de uma ruptura radical na sociedade. 
"uma sangrenta e penosa campanha militar que resultou em aproximadamente 500 mortos (5\% de toda a população do vale do Acre na época)" (NEVES, 2601-2003).

O quartel-general boliviano era "protegido por linhas de trincheiras e alambrados e a passagem pelo Rio Acre era impedida por uma grossa corrente de ferro e um canhão". Plácido de Castro, que tinha capturado o navio boliviano "Rio Afluá", renomeara como navio "Independência", encheu-o de borracha e baixava o Rio Acre com o objetivo de vender a borracha para o sustento das tropas e a compra de munição. Plácido de Castro, ao avistar o empecilho no Rio Acre, encarregou os soldados de limar a corrente, enquanto se preparava para passar a barreira, tendo o navio sob seu comando direto. Depois de "três dias de muitas mortes, os acreanos conseguiram romper a corrente que bloqueava o rio e passar com o vapor Independência” (NEVES, 26-01-2003).

Diante dos combates e das negociações para instalação do Bolivian Syndicate, o governo brasileiro toma precauções, temendo uma retomada dos conflitos, uma vez que o exército boliviano comandado pelo Presidente da República Manuel Pando se encontrava a caminho do Acre (vindo pelos Andes), e o exército de Plácido de Castro se mantinha mobilizado. Naquela ocasião, o Barão de Rio Branco ordena a ocupação militar da área revoltosa e convida a Bolívia a abrir negociações. O Tratado de Petrópolis foi assinado em novembro de 1903 e pôs fim aos conflitos fronteiriços dos brasileiros do Acre com a Bolívia. Terminada a questão com a Bolívia foi assinado em 1909 o Tratado do Rio de Janeiro (entre Brasil e Peru), que selou as fronteiras internacionais do Acre.

A Revolução Acreana é, portanto o evento histórico que "transforma" os brasileiros do Acre em acreanos. O acreano, enquanto povo, foi inventado a partir deste evento; antes não existiam acreanos nos altos rios e sim cearenses, maranhenses, pernambucanos, rio grandenses - ligados ao extrativismo da borracha - e, árabes, portugueses, sírios, libaneses, turcos - ligados ao comércio de mercadorias; todos viviam nos rios Acre, Purus, Xapuri, Iaco, Caeté e tantos outros. Esse povo só passou a ser denominado de acreano após a criação do Território Federal do Acre, em 1904. Antes desta data, o acreano (ex-nordes- 
tino, ex-cearense, o banido pela seca, o renegado) surgiu na relação com o chão (com o Acre, o rio) e, também, na relação com o outro (o boliviano).

\section{$\mathrm{O}$ mito fundador}

O mito fundador é o evento inaugural de uma narrativa que "impõe um vínculo interno com o passado, como um momento original" (CHAUÍ, 2006: 09). No Acre, o mito fundador é a Revolução Acreana, construído em torno da discussão da conquista do território que pertencia de fato aos bolivianos e peruanos e que fora ocupado e conquistado por nordestinos na passagem do século XIX para o XX. O sucesso desse mito fundador diz respeito ao fato do hoje território do Acre ter sido conquistado com esforços e recursos próprios, ou seja, o exército de seringueiros venceu os militares bolivianos e peruanos, sem a aquiescência do Governo brasileiro. Assim, no final da Revolução, os brasileiros do Acre conquistaram o direito de se autodenominarem acreanos (MORAIS, 2008).

O mito fundador é uma "invenção" também do presente, como ressalta Albuquerque Júnior (2007: 26), pois a invenção do "acontecimento histórico se dá no presente, mesmo quando se analisa as várias camadas de discursos que o constituíram ao longo do tempo". É o presente que interroga o passado e o conecta com a nossa vida, ancorado nos signos atribuídos ao passado. O termo invenção remete a uma "temporalização dos eventos, dos objetos e dos sujeitos", que pode ser tanto a "busca de um dado momento de fundação ou de origem", quanto o momento da "fabricação" ou "institucionalização de algo" (ALBUQUERQUE JÚNIOR, 2007).

Para Chaú, a fundação se refere a "um momento passado imaginário, tido como instante originário que se mantém vivo e presente no curso do tempo"; isso significa dizer que: "a fundação visa algo tido como perene", que "sustenta o curso temporal e lhe dá sentido". O momento fundante é permanentemente alimentado e atualizado. A força do mito do Acre permanece na memória coletiva, sendo de forma constante, enaltecido e reafirmado a fim de exaltar um patriotismo da incorporação do Acre ao território brasileiro. Essa característica do evento fundador é um dos objetivos do mito, o que "impõe um vínculo interno com o passado como origem, isto é, com um passado que não 
cessa nunca, que se conserva perenemente presente e, por isso mesmo, não permite o trabalho da diferença temporal e da compreensão do presente como tal" (CHAUÍ, 2006: 09).

O mito fundador, conforme ressalta Portelli (2006), não

é:

necessariamente uma história falsa ou inventada; é, isso sim, uma história que se torna significativa na medida em que amplia o significado de um acontecimento individual, ... transportando-o na formalização simbólica e narrativa das auto-representações partilhadas por uma cultura (PORTELLI, 2006: 120-121).

A acreanidade, propalada com o "Governo da Floresta", possui como "mito fundador" a Revolução Acreana que funda o Acre como unidade territorial e, o acreano, o protagonista da Revolução. Antes da Revolução Acreana não havia acreanos, mas tão-somente brasileiros do Rio Acre. E foi durante essa "luta que surgiu nossa identidade como povo". E "não podemos nunca nos esquecer que a primeira geração de acreanos não foi constituída por pessoas que aqui nasceram, mas por pessoas que pelo Acre deram suas vidas" (CALIXTO, 2003: 06).

A Revolução Acreana, como mito fundador do Acre, exerce uma forte coesão no imaginário coletivo. Os autonomistas, em diferentes momentos, também acionaram a Revolução como justificativa em suas reivindicações políticas com significados diferentes dos seringueiros, como se pode perceber a partir de extratos do manifesto dos autonomistas do Juruá de 1909:³

Conquistamos para a Nação, (o) ao índio pela nossa tenacidade e (o) ao estrangeiro pela efusão do nosso sangue esta terra magnífica e desconhecida; fomos os primeiros portadores da civilização ao ponto mais ocidental do Brasil e nesta cruzada poderosa continuamos a lidar; é justo, é lógico, que no convívio da federação brasileira tenhamos o nosso lugar (MESQUITA JÚNIOR ${ }^{4}, 2004:$ 34-35).

${ }^{3}$ Este manifesto foi publicado no livro comemorativo do centenário de "Cruzeiro do Sul", por iniciativa do gabinete do senador Geraldo Mesquita Júnior.

${ }^{4}$ O Manifesto dos Autonomistas foi publicado no livro Cruzeiro do Sul, organizado pelo senador 
Já os seringueiros, principalmente nas décadas de 1970 e 1980, justificavam que eram descendentes dos "veteranos do Acre", que prestaram serviços à Pátria ao lutarem em prol da incorporação do Acre ao Brasil e acionavam esse fato a fim de reivindicar a permanência nos seringais.

A Revolução Acreana fornece, por conseguinte, as referências identitárias do Acre, tanto as geográficas quanto as históricas; elege também os personagens qualificados pelos atributos de força, audácia, perseverança e honestidade acionado pelo discurso identitário da acreanidade. Em termos de personagens, Plácido de Castro e Luiz Galvez são os símbolos que consubstanciam a legitimidade política e a coroação do poder de luta dos brasileiros do Acre. Com Plácido de Castro é ressaltado o papel de libertador do Acre, aquele que organizou um exército de seringueiros e ganhou a guerra. E com Luiz Galvez é ressaltado o "discurso fundador" do Acre, o "Manifesto da Junta Revolucionária”, de 1899.

O discurso fundador, segundo Orlandi, é aquela fala "que transfigura o sem sentido em sentido" (ORLANDI, 2003[1993], p. 08); são aqueles discursos "que vão nos inventando um passado inequívoco" que vão nos "empurrando um futuro pela frente e que nos dá a sensação de estarmos dentro de uma história, de um mundo conhecido", e com isso contribui para a produção de um sentimento de pertencimento. O discurso fundador é enunciado que ecoa e produz "efeitos de nossa história em nosso dia-a-dia, em nossa reconstrução cotidiana, de nossos laços sociais, em nossa identidade histórica" (ORLANDI, 2003[1993], p. 12).

O Discurso Fundador pode ser tanto aquele que transforma o sem-sentido em sentido, quanto aquele que funda um sentido. $\mathrm{O}$ sentido, ao ser re-significado, se torna fundador de uma nova ordem a partir do discurso fundante. $\mathrm{O}$ mesmo pode ser fundado em qualquer época e traz em si sua relação com vários outros, que contribuem igualmente para re-significar (ORLANDI, [1990]2008). Nessa perspectiva o discurso fundador é, portanto, o que "instala as condições de formação" de outros, filiando-se à "sua própria pos-

Geraldo de Mesquita Júnior. 
sibilidade, instituindo em seu conjunto um complexo de formações discursivas", um sítio de significância que "configura um processo de identificação para uma cultura, uma raça, uma nacionalidade” (ORLANDI, 2003[1993], p. 24).

No caso do Manifesto da Junta Revolucionária, este diz respeito à indignação dos brasileiros do Acre contra a posse da Bolívia e contra a decisão do governo brasileiro de considerar as terras reivindicadas pelos "revolucionários do Acre" em território incontestavelmente boliviano. O sucesso do discurso fundador foi realçar o papel que tiveram os "acreanos" no encaminhamento da Revolução. A pátria abandonava-os e os revolucionários criaram outra; com essa frase têm-se a gênese do discurso fundador do Acre, o qual inaugura também o discurso do abandono político do governo federal em relação ao Acre (MORAIS, 2008).

No caso do Manifesto da Junta Revolucionária, este diz respeito à indignação dos brasileiros do Acre contra a posse da Bolívia e contra a decisão do governo brasileiro de considerar as terras reivindicadas pelos "revolucionários do Acre" em território incontestavelmente boliviano. Eis o que narra o discurso fundador acreano:

O Governo do Brasil não respondeu aos nossos patrióticos alarmes; a Pátria, a nossa estremecida mãe personificada em grupo de valentes e caritativos irmãos respondeu sem precisar de nosso apelo: a $1^{\circ}$ de maio $^{5}$, data que conservaremos gravada em nossos corações. Ilustres e denodados irmãos nos surpreenderam com a patriótica intimação que dirigiram em nome do povo brasileiro às autoridades bolivianas que, faltas de força e de prestígio, nos abandonaram com a mesma facilidade com que nos conquistaram. Sabemos da situação em que ficamos depois do abandono em que nos deixaram as autoridades brasileiras e isso vem demonstrar que os habitantes do Acre não pertencem à livre e grande pátria brasileira. É justo, pois, que cidadãos livres não se conformem com o estigma de parias criado pelo governo de sua pátria - nem podem de forma alguma continuar sendo escravos de uma outra nação: a Bolívia. Impôs-se a independência destes territórios, que elejam seu governo entre os cidadãos que trabalharam o seu

${ }_{5}^{5}$ Data do início da primeira insurreição acreana, quando um grupo de seringalistas deportou o chefe da aduana de Puerto Alonso. 
solo e exploraram suas riquezas; é, pois, chegado o momento de proclamar nossos indiscutíveis direitos de cidadãos livres. Cidadãos - escutai a proclama que ao povo dos territórios do Acre, Purus e Iaco dirige à Junta Revolucionária, manifestai vossa ilustre opinião a que sempre respeitamos; se não aceitais a independência continuaremos a sofrer as humilhações que nos impõe uma nação estrangeira; se, pelo contrário, aceitardes a independência, constituiremos o Estado Independente do Acre, valoroso, forte e digno, pelo patriotismo de seus filhos, poderoso pelas suas riquezas inesgotáveis que ousados estrangeiros nos querem usurpar (TOCANTINS, 2001, p. 327328).

O sucesso desse discurso fundador foi realçar o papel que tiveram os "acreanos" no encaminhamento da Revolução. A pátria abandonava-os e os revolucionários criaram outra; com essa frase têm-se a gênese do discurso fundador do Acre, o qual inaugura também o discurso do abandono político do governo federal em relação ao Acre. Para Toinho Alves, a Revolução foi feita para "promover, ao mesmo tempo e contraditoriamente, a independência e o pertencimento a uma pátria". Ela mobilizou os que não "tinham nada para lutar ao lado daqueles que os dominavam. E, assim, um exército de seringueiros famintos e dispersos venceu a guerra" (CARVALHO, 2002[1904], p. 07).

Os conflitos entre acreanos e bolivianos, nessa perspectiva, são investidos de uma aura de "epopéia" e "revolução"; os que participaram são considerados heróis, bravos, destemidos, invencíveis, grandes na guerra. Após o término dos conflitos, surge toda uma literatura exaltando os feitos de José Plácido de Castro. Isso contribuiu para a afirmação identitária pautada no patriotismo e heróísmo.

Os conflitos entre acreanos e bolivianos, nessa perspectiva, são investidos de uma aura de "epopéia" e "revolução"; os que participaram são considerados heróis, bravos, destemidos, invencíveis, grandes na guerra. Após o término dos conflitos, surge toda uma literatura exaltando os feitos de José Plácido de Castro. Isso contribuiu para a afirmação identitária pautada no patriotismo e heroísmo. Elucidativa dessa questão é o Hino Acreano, o hino da conquista, poema que foi escrito durante a guerra del Acre, que narra a história da incorporação do Acre e da invenção do povo acreano. 
Maria de Jesus Morais

\section{O Poema da Conquista}

O poema da conquista foi escrito pelo baiano Francisco Mangabeira em 1903. O médico Francisco Mangabeira nasceu em fevereiro de 1879, na casa onde havia falecido Castro Alves, adoeceu no Acre e morreu em 1904 voltando para a Bahia. A sua vida é reverenciada no Acre como de um herói, este antes de vir para o Acre já tinha estado em Canudos. Este fez parte da "primeira turma de acadêmicos, que offereceram seus serviços gratuitos ao governo e seguiram para o campo da luta crudelíssima" (SILVEIRA, 2002, p. 50). Da luta sertaneja de Canudos, Mangabeira escreveu alguns poemas e foi atraído para a Amazônia em busca de emprego. Francisco Mangabeira chegou ao Acre em 1903, onde exerceu as funções de médico e de correspondente no Diário de Notícias. O contexto em que escreveu o poema da conquista é assim descrito:

Seringal Capatará, outubro de 1903. Na propriedade de Plácido de Castro que serviu como quartel-general das forças revolucionárias, os últimos embates com os bolivianos ainda eram uma marca recente na vida dos homens ali alojados. Espalhados em suas barracas e envoltos às imagens dos companheiros perdidos na luta, os soldados da revolução viviam entre a alegria de um novo tempo e os rumores de que os bolivianos avançavam novamente para o Acre, dispostos a retomar a luta pelo território (SILVEIRA, 2002, p. 07).

Na década de 1920 o então prefeito departamental, Epaminondas Jacome, oficializou o poema como hino acreano, vejamos trecho do despacho: "que seja adotado nas escolas públicas deste departamento o Hino Acreano" e recomendava que os professores providenciassem para "que os respectivos alunos o exercitem nas mesmas escolas, prestando dest'arte, uma justa homenagem ao seu autor e aos demais denodados patrícios que se sacrificaram pela causa do Acre" (SILVEIRA, 2002, p. 27).

O poema da conquista oficializado hino acreano foi escrito "sob o impacto das batalhas em 1903" pelo poeta que "assistia os feridos das lutas no seringal Capatará", sede do comando revolucionário de Plácido de Castro (SILVA, 1996, p. 90). Vejamos a letra do hino acreano:

Que este sol a brilhar soberano 
Sobre as matas que o vêem com amor

Encha o peito de cada acreano

De nobreza, constância e valor...

Invencíveis e grandes na guerra,

Imitemos o exemplo sem par

Do amplo rio que briga com a terra

Vence-a e entra brigando com o mar

Fulge um astro na nossa bandeira

Que foi tinto no sangue de heróis

Adoremos na estrela altaneira

O mais belo e o melhor dos faróis

Triunfantes da luta voltando

Temos n'alma os encantos do céu

$\mathrm{E}$ na fronte serena, radiante,

Imortal e sagrado troféu

O Brasil a exultar acompanha

Nossos passos, portanto é subir

Que da glória a divina montanha

Tem no cimo o arrebol do porvir

Possuímos um bem conquistado

Nobremente com armas na mão

Se o afrontarem, de cada soldado

Surgirá de repente um leão

Liberdade é o querido tesouro

Que depois do lutar nos seduz

Tal o rio que rola, o sol de ouro

Lança um manto sublime de luz

Vamos ter como prêmio da guerra

Um consolo que as penas desfaz

Vendo as flores do amor sobre a terra

E no céu o arco-íris da paz

As esposas e mães carinhosas

A esperarem nos lares fiéis

Atapetam a porta de rosas

E cantando entretecem lauréis

Mas se audaz estrangeiro algum dia

Nossos brios de novo ofender

Lutaremos com a mesma energia

Sem recuar, sem cair, sem temer

E ergueremos, então, destas zonas 
Um tal canto vibrante e viril

Que será como a voz do Amazonas

Ecoando por todo o Brasil

O poema consagra o heroísmo acreano na conquista do seu território, marca e apresenta o nascimento do Acre e dos acreanos e, ao lado da bandeira criada por Luiz Galvez consagra os símbolos cívicos do Estado. $\mathrm{Na}$ bandeira, sobressai a importância do sentido alegórico da estrela vermelha, em associação à luta dos acreanos que derramaram o sangue para defender a soberania do "seu solo". Essa alusão é re-significada e retomada desde a campanha para o governo estadual no pleito eleitoral de 1990, pelo grupo político, formado principalmente pelo PT, que se constituiria mais tarde (1999) no Governo da Floresta.

Outra obra que traz considerações sobre o sentido da Revolução Acreana como ato patriótico foram os escritos de Euclides da Cunha. Euclides da Cunha foi enviado pelo Ministério das Relações Exteriores à Amazônia na condição de chefe, pelo Brasil, da Comissão Mista Brasileiro-Peruano de Reconhecimento do Alto Purus (1904-1905), ${ }^{6}$ com vistas a fixar os limites entre o Brasil (Acre) e Peru.

Euclides da Cunha, em À Margem da História (1999[1909]), também salienta a coragem e o patriotismo dos seringueiros nordestinos, os quais, mesmo vivendo em condições subumanas, prisioneiros do sistema de aviamento e da hostilidade da floresta, foram exemplos de brasilidade. Para ele o sertanejo é o conquistador, um herdeiro e continuador dos sertanistas, dos entradistas, com a diferença de fixar-se na terra, ocupar e domar o território sob as mais adversas condições. Na Amazônia, o Brasil sertanejo ganha outro sujeito, o seringueiro, o "desbravador das fronteiras". Os seringueiros, para Euclides da Cunha, são os homens que se fizeram mais fortes que a terra, para dominá

${ }^{6}$ Das informações da viagem de Euclides da Cunha ao Rio Purus foram produzidas as seguintes obras: em 1905 Euclides da Cunha entregou ao Barão do Rio Branco o Relatório de Reconbecimento; em 1906 as Notas Complementares. Em 1907 publicou Contrastes e Confrontos, livro com matérias jornalísticas publicadas em 1904 e publicou também o livro Peru versus Bolivia. Em 1909 foi publicado o livro póstumo À Margem da História, título escolhido por Euclides da Cunha para o seu segundo livro vingador. E das informações do Relatório e das Notas Complementares juntamente com as cartas que escreveu durante a missão, resultou o livro Um Paraíso Perdido, publicado em 1976. 
-la, e a esses homens coube a tarefa "heróica" de povoar e ampliar as fronteiras territoriais do Brasil, com a incorporação do Acre ao território nacional.

Segundo a narrativa euclidiana, o migrante nordestino foi exortado para a Amazônia, este era um expatriado dentro da pátria. Os migrantes foram embarcados nos navios por preocuparem os poderes públicos quanto aos estragos que poderiam provocar nas cidades, e, nunca foram acompanhados por médicos ou agentes oficiais. Os banidos, disse Cunha (2000: 150), "levavam a missão dolorosíssima e única de desaparecerem”. Porém não desapareceram; ao chegarem aos altos rios, estes locais, que eram vagas expressões geográficas, "em menos de trinta anos, cem mil sertanejos, ou cem mil ressuscitados, apareciam inesperadamente e repatriavam-se de um modo original e heróico, dilatando a pátria até aos terrenos novos que tinham desvendado" (CUNHA, 2000, p. 150 151).

A questão do patriotismo e brasilidade teve no professor Craveiro Costa, com o livro "A Conquista do Deserto Ocidental", um grande alimentador dessa idéia de patriotismo, de um ímpeto de brasilidade e de orgulho nacional: a empreitada dos brasileiros do Acre. Craveiro Costa viveu no Território Federal do Acre, no Departamento do Alto Juruá, na década de 1910; foi Diretor da Instrução Pública do Vale do Juruá e Diretor do Grupo Escolar Barão do Rio Branco; foi também autonomista do Juruá (movimento que criticava a situação de Território Federal para o Acre) e participou dos levantes de 1909 e 1918. O livro foi publicado pela primeira vez em 1924, com o titulo O Fim da Epopéia. Os argumentos utilizados pelo autor, nesta obra, têm um caráter inconformado com a criação do Território Federal do Acre e com o assassinato de Plácido de Castro, questão essa que tem alimentado, ainda hoje, o discurso identitário do Acre. E continua sendo leitura obrigatória no que se refere à insatisfação dos acreanos com a situação de Território Federal. Prova disso é o fato deste livro ter sido reeditado várias vezes no Acre, em 1940, em 1978, em 1998, em 2003 e em 2005.

Outro autor que contribuiu com o ideal patriótico do acreano foi Abguar Bastos (1931, p. 47), romancista das décadas de 1920 e 1930. O mesmo destaca o caráter territorializador do nordestino no Acre. Nos trechos 
abaixo, o autor faz uma representação poética da conquista do território, da chegada do migrante, do cearense:

O cearense e o Acre eram dois destinos ainda sem comunicação com a vida: o primeiro à procura duma terra que o recebesse, o segundo em busca de um povo que o tomasse. Ambos soturnos, ásperos, trágicos. Ambos libertando das costas um deserto agressivo. Um carregado de filhos. Outro carregado de rios (BASTOS, 1927, p. 13).

E continua:

A terra não tinha amor ao seu dono (no caso o boliviano). Com as suas florestas desgrenhadas e as suas sombras lascivas, preferia entregar-se ao estrangeiro que vinha do Brasil com o cheiro do mar nas carnes rijas. Cada vez chegava mais gente do Ceará. A terra ali estava inacessível e áspera. Os rios passavam velozes procurando o seu leito. Os cearenses também. E a terra parecia mais mansa. Pouco a pouco o boliviano foi sentindo o desamor das plagas adúlteras. Cada vez mais a sua taciturna indiferença tornava o vale alheio aos seus carinhos. Pelas veias impetuosas duma gigantesca potamografia as águas arremessavam os índios para o ocidente. $\mathrm{O}$ boliviano parecia estrangeiro. O cearense parecia o dono da casa (BASTOS, 1931, p. 47).

O historiador e jurista José Moreira Brandão Castelo Branco, morador do Vale do Juruá no período de 1909 a 1934, foi responsável por grande produção de registros sobre a história do Acre, os quais foram publicados na Revista do IHGB do Rio de Janeiro. O jurista Castelo Branco (1961) ressaltava que, apesar das dificuldades, como a:

distância, o estranho sistema de trabalho e a falta de assistência, o 'brabo' venceu essa derradeira etapa, fazendo emergir de um meio inteiramente selvagem, no 'ultimo oeste' brasileiro, um extenso e opulento território devido à intensidade de sua produção industrial e ao movimento comercial daí sobrevindo (CASTELO BRANCO, 1961, p. 151-152).

Esses são alguns exemplos de obras, anteriores ao Governo da Floresta, que ressaltam o caráter patriótico da Revolução Acreana, realizada pelo "exército de seringueiros", sob comando de Plácido de Castro. 


\title{
The BORDER AS FUNDING MYTH OF ACRE AND OF THE ACREANS
}

\begin{abstract}
This article aims at investigating the invention of the idea of "Acreanidade" as part of the agenda of the local political leadership since 1999, self-proclaimed as the "Rainforest Government". Taking Orlandi (2006), Chauí (2007) e Albuquerque J. (2003) as starting points, the analysis will focus on the funding myths of "Acre", and of the "Acreans" and the "Acrean Revolution", which, articulated in the autonomist movement that claimed the passage of the Acre from federal territory to state, and in the historical process of fights for the land, conducted by rubber tappers and indigenous people, created the scaffolding for a historical identity which, assimilated by the official discourse, is used to legitimate the interests of those who share an empathy with the "history written by the victors".
\end{abstract}

KEYWORDS: Acreanidade. Funding Myth. Acre Revolution. Rainforest Government. Discourse.

\section{Referências}

ALBUQUERQUE JÚNIOR, D. M. História: a arte de inventar o passado. Bauru: EDUSC, 2007.

CARVALHO, J. A Primeira Insurreição Acreana (documentada). Rio Branco: FEM, 2002.

CASTELO BRANCO, J. M. B. Povoamento da Acreania. Rio de Janeiro, Revista do IHGB, volume 250, 1961.

CHAUÍ, M. Brasil: mito fundador e sociedade autoritária. São Paulo: Perseu Abramo, 2006.

MORAIS, M. de J. "Acreanidade": invenção e reinvenção da identidade acreana. Niterói: UFF, 2008. (Tese de Doutorado em geografia).

NEVES, M. V. Quatro anos de Revolução, seis meses de guerra. Rio Branco: Jornal Página 20, 26-01-2003.

ORLANDI, E. P. (Org.). Discurso Fundador: a formação do país e a construção da identidade nacional. Campinas: Pontes, 2003.

ORLANDI, E. P. Terra á Vista: discurso do confronto: Velho e Novo Mundo. Campinas: UNICAMP, 2008. 
PORTELLI, A. O Massacre de Civitella Val di Chiana (Toscana: 29 de junho de 1944): mito, política, luto e senso comum. In: FERREIRA, M. de M. \& AMADO, J. Usos e Abusos da História Oral. Rio de Janeiro: FGV, 2006.

RAFFESTIN, C. Por uma Geografia do Poder. São Paulo: Ática, 1993.

SACK, R. Human Territoriality: its theory and history. Cambridge: Cambridge University Press, 1986.

SILVA, L. M. R. da. Procura-se uma Pátria: a literatura no Acre (1900-1990). Porto Alegre, 1996. Tese (Doutorado em Letras) PUCRS.

SILVEIRA, V. V. Por Trás do verso e da melodia do Hino Acreano. Rio Branco: Tribunal de Justiça do Estado do Acre, 2002.

Data de recebimento: 16/07/2014

Data de aceite: 21/09/2014 